\title{
High temperature digital image correlation evaluation of in-situ failure mechanism: An experimental framework with application to C/SiC composites
}

\author{
W. G. Mao ${ }^{1,2, ~ *}$, J. Chen ${ }^{1}$, M. S. $\mathrm{Si}^{1}$, R. F. Zhang ${ }^{1}$, Q. S. Ma ${ }^{3, *}$, \\ D. N. Fang ${ }^{4}, X$. Chen ${ }^{2}$ \\ ${ }^{1}$ School of Materials Science and Engineering, Xiangtan University, Hunan 411105, China \\ ${ }^{2}$ Department of Earth and Environmental Engineering, Columbia University, New York \\ 10027, United States of America \\ ${ }^{3}$ Science and Technology on Advanced Ceramic Fibers and Composites Laboratory, National \\ University of Defense Technology, Changsha 410073, PR China \\ ${ }^{4}$ State Key Lab for Turbulence and Complex Systems, Peking University, Beijing, 100871, \\ China
}

\begin{abstract}
A high temperature digital image correlation (DIC) technique was developed, which was applied to study the in-situ fracture behavior of a carbon fiber reinforced silicon carbide matrix $(\mathrm{C} / \mathrm{SiC})$ composite. The displacement distribution and cracking information of the $\mathrm{C} / \mathrm{SiC}$ single edge notched beam specimen can be monitored real-time, thanks to the improved DIC technique with special speckle patterns that can reach up to $1600{ }^{\circ} \mathrm{C}$. The results showed that the brittle to ductile transition temperature of $\mathrm{C} / \mathrm{SiC}$ composites is about $1300{ }^{\circ} \mathrm{C}$. The new failure mechanisms of $\mathrm{C} / \mathrm{SiC}$ composites at different experimental temperatures were further verified with the aid of X-ray diffraction and scanning electron microscope (SEM) techniques. In addition, the relationships between the fracture toughness, first-crack strength of $\mathrm{C} / \mathrm{SiC}$ composites and environmental temperature were deduced. The proposed experimental method and testing results may shed some light on assessing the reliability and durability of $\mathrm{C} / \mathrm{SiC}$ composites at high temperatures.
\end{abstract}

Keywords $\mathrm{C} / \mathrm{SiC}$ composites; Mechanical properties; Digital image correlation; High-temperature testing; Brittle to ductile transition

\footnotetext{
* Corresponding authors: W. G. Mao, Email: ssamao@126.com; Q. S. Ma, Email: nudtmqs1975@163.com.
} 


\section{Introduction}

Many ceramic matrix composites are employed at high temperature and their durability is of top concern. For example, the continuous carbon fibre reinforced SiC matrix composites $(\mathrm{C} / \mathrm{SiC})$ have been extensively used in the structures of modern aviation vehicles, including rocket nozzles, aeronautic jet engines, heat shields and aircraft braking materials, to name a few. $\mathrm{C} / \mathrm{SiC}$ composites show superior physical properties such as high temperature resistance, high damage tolerance, low density, desirable corrosion resistance, high wear resistance, and plausible frictional characteristics $[1,2]$. In a working environment with high temperature exceeding $1000{ }^{\circ} \mathrm{C}$ or higher, the fracture strength, fracture toughness, residual stresses, hardness, thermal and oxidation resistance play an important role in the mechanical integrity of $\mathrm{C} / \mathrm{SiC}$ composites.

In recent years, various experimental methods such as tension [3-6], shear [7-9] and bending tests [10-12] have been developed to measure the fracture strength and fracture toughness of ceramic matrix composites. Tao et al. found that the tensile strength of 2D-C/SiC composites decreased from $266 \mathrm{MPa}$ at room temperature to $146 \mathrm{MPa}$ at $1000{ }^{\circ} \mathrm{C}$ [3]. Wang et al. studied that the shear strength of $2 \mathrm{D}-\mathrm{C} / \mathrm{SiC}$ composites increased from $27 \mathrm{MPa}$ at room temperature to $35 \mathrm{MPa}$ at $1200{ }^{\circ} \mathrm{C}$ [7]. $\mathrm{Hu}$ et al. evaluated that the fracture strengths of $2 \mathrm{D} \mathrm{C} / \mathrm{SiC}-\mathrm{TaC}$ composites by bending tests were about $246 \mathrm{MPa}$ at room temperature, $98 \mathrm{MPa}$ at $1800{ }^{\circ} \mathrm{C}$, and $122 \mathrm{MPa}$ $2000{ }^{\circ} \mathrm{C}$, respectively [13]. Yin et al. found that the flexural strength of the SiBC modified $\mathrm{C} / \mathrm{SiC}$ composites changed from 276 to $440 \mathrm{MPa}$ at different temperatures [14]. Despite of these progresses, an in-situ experimental technique that could directly observe the fracture characteristics at high temperature is still lacking. Such an in-situ measurement may help to further clarify the fracture mechanism and obtain more 
reliable high-temperature material properties, and thus useful for predicting the reliability and durability of $\mathrm{C} / \mathrm{SiC}$ composites in practice.

However, it is commonly known that at high temperature above over $1000{ }^{\circ} \mathrm{C}$, thermal drift imposes a huge challenge for traditional strain gauge and laser displacement sensor methods, making the sensor-based in-situ measurement difficult. As we know, the digital image correlation (DIC) technique has been gradually regarded as a powerful tool of displacement/strain measurement at different temperatures and scales $[15,16]$. To our knowledge, very few works in literature have directly used DIC technique to study the fracture mechanism of composites at high temperatures.

In this work, three-dimensional $\mathrm{C} / \mathrm{SiC}$ composites were first fabricated by the precursor infiltration and pyrolysis (PIP) method. Fracture characteristics and crack extension of $\mathrm{C} / \mathrm{SiC}$ samples were systematically studied within a range from $1000{ }^{\circ} \mathrm{C}$ to $1600{ }^{\circ} \mathrm{C}$ by combining single edge notched beam (SENB) and DIC techniques. The present study emphasizes the in-situ observation and analysis of the first crack propagation features under various temperatures. The high-temperature mechanical properties and fracture resistance of $\mathrm{C} / \mathrm{SiC}$ composites were obtained. The established experimental framework may be beneficial for revealing the high-temperature fracture behavior of composite materials under practical working conditions at high temperature.

\section{Experimental}

\subsection{Sample preparation}

Polycarbonsilane powder with molecular weight of 1400-1800 and soften point $175{ }^{\circ} \mathrm{C}$ was synthesized in our laboratory. Three-dimensional braided carbon fibers 
were used as the reinforcement. Firstly, the polydimethylsilane was decomposed in an autoclave under $\mathrm{N}_{2}$ when the temperature was within $350-500{ }^{\circ} \mathrm{C}$. Secondly, the products were dissolved in xylene, and then the impurities were filtrated. Finally, the PCS was fabricated from the solution by the reduced pressure distillation. Xylene was used as solvent for PCS. The $\mathrm{C} / \mathrm{SiC}$ samples were prepared by using 12-18 cycles infiltration of PCS-xylene solution and subsequently pyrolysis at $1200{ }^{\circ} \mathrm{C}$ under an inert atmosphere. The fiber volume fraction and the braiding angle of the composites were designed as $36.3 \%$ and $24.8^{\circ}$, respectively (see Fig. 1). According to the ASTM standard E1820-05a [17], these C/SiC composites were cut into the rectangular-shape specimens with $40 \mathrm{~mm} \times 5.5 \mathrm{~mm} \times 4.5 \mathrm{~mm}$. All specimens were polished with 2.5 $\mu \mathrm{m}$ diamond paste before bending tests. The pre-notch was made by a commercial cutting machine with a very thin diamond saw blade, whose direction was perpendicular to the length direction of the specimen. The width and depth of the narrow notch were about $300 \mu \mathrm{m}$ and $1.8 \mathrm{~mm}$, respectively (see Fig. 2). The similar work was shown in our previous results [18]. Finally, the specimens were cleaned by an ultrasonic oscillator with distilled water, and then completely dried before bending tests. The total thirty-two SENB specimens have been prepared in our tests.

\subsection{SENB tests under high temperatures}

Fig. 3(a) shows the schematic of the whole bending test equipment with the aid of DIC system. The change of strain in the most dangerous region (marked with dashed red lines) was real time monitored by DIC. SENB tests were performed by a universal testing machine (No. WDTI-5) in air, as shown in Fig. 3(b). The experimental temperature was set as room temperature, $1000{ }^{\circ} \mathrm{C}, 1100{ }^{\circ} \mathrm{C}, 1200{ }^{\circ} \mathrm{C}$, $1300{ }^{\circ} \mathrm{C}, 1400{ }^{\circ} \mathrm{C}, 1500{ }^{\circ} \mathrm{C}$ and $1600{ }^{\circ} \mathrm{C}$, respectively. The detailed high-temperature test order was that the furnace was firstly heated up to the designated temperature, and 
then the $\mathrm{C} / \mathrm{SiC}$ sample was firstly pasted beneath the upper indenter by using a kind of high-temperature resistance glue. And then $\mathrm{C} / \mathrm{SiC}$ sample and the indenter were set into the furnace together through the hole on the top surface of the furnace. In order to ensure the whole sample temperature close to the furnace temperature, each sample stayed in the furnace about 10 min prior to bending tests. The tensile machine was controlled by a speed mode of $0.05 \mathrm{~mm} / \mathrm{min}$. It is seen from Fig. 3(b) that a resolution $1624 \times 1236$ pixels charge coupled device camera (GOM Co., Germany) equipped with a lens of $50 \mathrm{~mm}$ focal length was used to observe and record the dynamic movements of the patterns. The frame rate of the camera can achieve up to $15 \mathrm{~Hz}$, with reduced image resolution up to $30 \mathrm{~Hz}$. The sampling rate of the camera was set as one image per second in this work. The detailed information was described in our previous works [16, 18-22]. In order to observe the crack nucleation and propagation patterns clearer, we added a telephoto zoom Nikon lens and a $490 \mathrm{~nm}$ optical band pass filter in front of the camera (see Fig. 3(b)). The maximum optical enlargement factor and adjustable focal length range of the lens are $200 \mathrm{X}$ and $80-400 \mathrm{~mm}$, respectively. The aim is to obtain more detailed strain information under smaller scales. Two illumination white lights (GOM Co., Germany) were used to compensate the light intensity and decrease the influence of high temperature thermal radiation. During the DIC measurements, the interesting region was divided into a lot of small square reference subsets of $29 \times 29$ pixels. The gap between two subsets was $7 \times 7$ pixels. The scale factor was $0.1 \mathrm{~mm} /$ pixels. The strain post-processing analysis was achieved with the available commercial DIC professional software (ARAMIS, Version 6.2, GOM Co., Germany).

In order to in-situ measure the displacement evolution at high temperatures, we developed a kind of high temperature resistance special speckle patterns, instead of 
the traditional speckle patterns only used under room temperature. Our speckle patterns consisted of a high-temperature-resistance glue and $\mathrm{ZrO}_{2}$ powder with the size $10-20 \mu \mathrm{m}$, which were sprayed into the specimen surface by using high-pressure airbrush guns. The glue has a good adhesive ability up to $1750{ }^{\circ} \mathrm{C}$. In addition, the melting point of $\mathrm{ZrO}_{2}$ powder is much higher than our experimental temperatures. All samples thus coated were dried about 15 hours at room temperature, and then dried about 2 hours in the furnace under $80{ }^{\circ} \mathrm{C}$ and another 2 hours under $150{ }^{\circ} \mathrm{C}$, as shown in Fig. 2. The extension of the DIC technique for high temperature deformation measurements of metal and composites [23-25] has validated the feasibility and reliability of the non-destructive DIC technique in high-temperature tests.

The experimental data was recorded by computers for estimating the material properties of $\mathrm{C} / \mathrm{SiC}$ specimens. The fracture strength, $\sigma_{b}$, and fracture toughness, $K_{\mathrm{IC}}$, of $\mathrm{C} / \mathrm{SiC}$ composites can be obtained by the following equations [20, 26, 27],

$$
\begin{gathered}
\sigma_{b}=\frac{3 P L}{2 B w^{2}} \\
K_{\mathrm{IC}}=Y \frac{3 P L}{2 B w^{2}} \sqrt{a}
\end{gathered}
$$

where $P$ denotes the bending load, $a$ is the initial length of the pre-existed notch, $B$ and $w$ are, respectively, the width and height of the sample. $L$ is the span between two lower supporting points and it equals $18 \mathrm{~mm}$, and $Y$ is usually defined as a function of $a / w$. In the case of $L / w=4, Y$ can be represented as the following exponential polynomial form [18],

$$
Y=1.93+3.07 \frac{a}{w}+14.53\left(\frac{a}{w}\right)^{2}-25.11\left(\frac{a}{w}\right)^{3}+25.8\left(\frac{a}{w}\right)^{4}
$$




\subsection{XRD analysis and SEM observations}

The oxidation characteristics of $\mathrm{C} / \mathrm{SiC}$ composites were analyzed by $\mathrm{X}$-ray diffraction (XRD, Ultima IV, Rigaku, Japan) before and after the experiment. And the microstructures of the fracture surfaces were observed using a scanning electron microscope (SEM, JSM-6380LV, JEOL, Japan) after the experiment.

\section{Results and discussion}

\subsection{Fracture analysis of $\mathrm{C} / \mathrm{SiC}$ under high temperatures}

The relationships among bending load, deflection and test time curve in $\mathrm{C} / \mathrm{SiC}$ composites are plotted in Fig. 4. It can be seen that the carrying capacity change of $\mathrm{C} / \mathrm{SiC}$ composites gradually reduce as the test temperature increases from room temperature to $1600{ }^{\circ} \mathrm{C}$. It is interesting to note that when the test temperature is lower than $1300{ }^{\circ} \mathrm{C}$, the mechanical behavior of $\mathrm{C} / \mathrm{SiC}$ displays apparent brittle fracture features. It can be observed from Fig. 4 that the evolution of bending loads in those curves of lower $1300{ }^{\circ} \mathrm{C}$ monotonically increase, and then suddenly decrease when the rupture phenomenon of $\mathrm{C} / \mathrm{SiC}$ sample occurs. After that, the curve gradually decays thanks to the remaining reinforcement from the carbon fibers. However, when the testing temperature exceeds $1300{ }^{\circ} \mathrm{C}$, the $\mathrm{C} / \mathrm{SiC}$ composites show ductile fracture characteristics, where the load-displacement curve shows no sign of abrupt reduction. Therefore, the brittle to ductile transition temperature for $\mathrm{C} / \mathrm{SiC}$ composites can be estimated as $1300{ }^{\circ} \mathrm{C}$ in the present study, which was also verified by the subsequent results. Note that in the literature, Yashiro et al. found that the fracture feature of plain-woven SiC/SiC composites after thermal loading displayed brittle behavior at $1000{ }^{\circ} \mathrm{C}[27]$.

It is essential to determine the critical displacement/strain data by using DIC corresponding to the first crack formation under different test temperatures. Fig. 5 
shows the relationship of the representative longitudinal strain, $\varepsilon_{x x}$, in front of the pre-existed notch tip and test time, $t$, under the same controlled mode of $0.05 \mathrm{~mm} / \mathrm{min}$. Generally, $\varepsilon_{x x}$ gradual increases linearly with load time before the crack first nucleates (see the fitted green line in inset of Fig. 5), where the test temperature is $1300{ }^{\circ} \mathrm{C}$. However, when $t$ is larger than $257 \mathrm{~s}, \varepsilon_{x x}$ increases quickly and becomes another state (see the fitted black line in inset of Fig. 5). This transition process means that the first new crack may form. To determine the critical transition location and obtain the corresponding critical bending load, the $\varepsilon_{x x}$ data was linearly fitted in different growth stages, respectively. The two fitted green and black lines intersect at point A. Another line can be plotted along the half of the angle, which intersects with the actual experimental curve at point B. Therefore, the test time at point B can be approximately regarded as the critical fracture time. Furthermore, according to this critical time, the critical bending load $P_{\mathrm{cr}}^{\mathrm{DIC}}$ and longitudinal strain $\varepsilon_{x x}^{c r i}$ can be determined by using the recorded data, respectively. For this case in Fig. 4, the critical time is $257 \mathrm{~s}$ and the corresponding strain, $\varepsilon_{x x}^{c r i}$, equals to about $2.76 \%$. The similar analysis was discussed in our previous work [18, 19]. Likewise, the first-crack nucleation of $\mathrm{C} / \mathrm{SiC}$ samples under other testing temperatures can be evaluated.

Fig. 6 shows the change of strain mappings, $\varepsilon_{x x}$, near the notch with bending loads under different temperatures. It can be seen from Fig. 6(a) that $\varepsilon_{x x}$ does not show apparent change under room temperature within the small elastic deformation phase until the test time, $t$, increases up to $271 \mathrm{~s}$. After this time point, a crack gradually nucleates and grows along the weakest region in front of the pre-existed notch, as shown in Fig. 6(a). Eventually, it results in the sample rupture when $t$ equals about 446 s. The whole load-deflection-test time curve is shown in Fig. 4 with black 
line. Similarly, it is shown in Figs. 6(b), (c) and (d) that the evolution of $\varepsilon_{x x}$ in C/SiC composite samples varies with bending loads at $1100{ }^{\circ} \mathrm{C}, 1300{ }^{\circ} \mathrm{C}$ and $1600{ }^{\circ} \mathrm{C}$, respectively. It is interesting to find that the critical bending load, test time and fracture features of the new cracking in $\mathrm{C} / \mathrm{SiC}$ composites at high temperatures apparently differ from those under room temperature. For the case $1100{ }^{\circ} \mathrm{C}$, the DIC analysis shows that the critical bending load and cracking formation time are about 170.6 N and 200 s, respectively, as shown in Fig. 6(b). Similarly, fig. 6(c) shows that the critical bending load and time of $\mathrm{C} / \mathrm{SiC}$ samples under $1300{ }^{\circ} \mathrm{C}$ are approximately 141.7 N and 257 s, respectively. Furthermore, the corresponding experimental data is 92.1 $\mathrm{N}$ and $375 \mathrm{~s}$ under $1600{ }^{\circ} \mathrm{C}$ test, respectively. As discussed above, the brittle transition ductile temperature of $\mathrm{C} / \mathrm{SiC}$ composite has estimated as $1300{ }^{\circ} \mathrm{C}$. Therefore, for bending tests at $1600{ }^{\circ} \mathrm{C}$, the ductility of $\mathrm{C} / \mathrm{SiC}$ composites displays more apparent. It may weaken the load carrying capacity of $\mathrm{C} / \mathrm{SiC}$ and result in the increasing of the critical cracking nucleation time 375 s. Our experimental data fully reveals that high temperature environments play a significant role in changing the mechanical behaviors of $\mathrm{C} / \mathrm{SiC}$ composites. In addition, it is interesting to observe that the configurations of the new cracking propagation paths under $1100{ }^{\circ} \mathrm{C}, 1300{ }^{\circ} \mathrm{C}$ and $1600{ }^{\circ} \mathrm{C}$ are almost linear, which differs from that monitored at room temperature. The reason may be attributed that high-temperature oxidation during the sample installation and bending tests increases quickly the interface adhesion strength between carbon fibre and SiC matrix.. These experimental phenomena also mean that it is more valuable to in-situ study the high temperature fracture process of $\mathrm{C} / \mathrm{SiC}$ composites, and obtain more comprehensive information to predict their service life and reliabilities.

To further explain the influence of high temperatures on $\mathrm{C} / \mathrm{SiC}$ composites, the 
first-crack fracture strength, $\sigma_{b}$, and the first-crack fracture toughness, $K_{\text {IC }}$, of $\mathrm{C} / \mathrm{SiC}$ composites were estimated by using equations (1) and (2), as shown in Fig. 7. $\sigma_{b}$ decreases from 96.97 $\mathrm{MPa}$ at room temperature to $29.73 \mathrm{MPa}$ at $1600{ }^{\circ} \mathrm{C}$. Similarly, $K_{\mathrm{IC}}$ gradually reduces from $8.55 \mathrm{MPa} \cdot \mathrm{m}^{1 / 2}$ to $2.26 \mathrm{MPa} \cdot \mathrm{m}^{1 / 2}$. Both $\sigma_{b}$ and $K_{\mathrm{IC}}$ at $1600{ }^{\circ} \mathrm{C}$ decrease approximately $30 \%$, compared with those at room temperature. As the best of our knowledge, the relative work about the first crack strength of $\mathrm{C} / \mathrm{SiC}$ composite was not found. Shi et al. found that the tension strength of $\mathrm{KD}-\mathrm{I}(\mathrm{f}) / \mathrm{SiC}$ composites showed a big decline from a room temperature value of $350 \mathrm{MPa}$ to $200 \mathrm{MPa}$ at $1300{ }^{\circ} \mathrm{C}$ [28]. Li et al studied that the fracture strength of $\mathrm{ZrB}_{2}-\mathrm{SiC}$ composites ranges from $450 \mathrm{MPa}$ at room temperature to $200 \mathrm{MPa}$ at $1800{ }^{\circ} \mathrm{C}$ [29]. Wan et al. measured that the fracture toughness of $\mathrm{C} / \mathrm{SiC}$ composites varied in the range of $6.06-4.09 \mathrm{MPa} \cdot \mathrm{m}^{1 / 2}$ from room temperature to $2000{ }^{\circ} \mathrm{C}$ [30]. Fang et al. investigated the fracture toughness of the hot pressed $\mathrm{SiC}$ matrix composites decreased linearly from $5.7 \mathrm{MPa} \cdot \mathrm{m}^{1 / 2}$ at room temperature to $3 \mathrm{MPa} \cdot \mathrm{m}^{1 / 2}$ at $1300{ }^{\circ} \mathrm{C}$ in air, and reduced to $2.14 \mathrm{MPa} \cdot \mathrm{m}^{1 / 2}$ at $1800{ }^{\circ} \mathrm{C}$ in vacuum rapidly [31]. Our experimental results are within the same order of magnitude.

\subsection{X-ray diffraction (XRD) and scanning electron microscope (SEM) analysis}

To clarify the effect of high temperature test environment on the structure of $\mathrm{C} / \mathrm{SiC}$ composites, we have performed the XRD pattern and SEM analysis after bending tests. Fig. 8 shows the change of $\mathrm{XRD}$ pattern of $\mathrm{C} / \mathrm{SiC}$ composites after bending tests. It can be found carbon and silicon carbide phases during tests at room temperature. However, when the tests were undertaken at high temperatures, the carbon phase gradually vanishes because the carbon fiber materials are easier to be oxidized. On the other hand, the silicon dioxide phase occurs. Furthermore, the higher the test temperature is, the stronger the silicon dioxide phase is. The reason may be 
explained by the following reactions [32-34],

$$
\begin{aligned}
& 2 \mathrm{SiC}(\mathrm{s})+3 \mathrm{O}_{2}(\mathrm{~g}) \rightarrow 2 \mathrm{SiO}_{2}(\mathrm{~s})+2 \mathrm{CO}(\mathrm{g}) \\
& \mathrm{SiC}(\mathrm{s})+2 \mathrm{O}_{2}(\mathrm{~g}) \rightarrow \mathrm{SiO}_{2}(\mathrm{~s})+\mathrm{CO}_{2}(\mathrm{~g}) \\
& \mathrm{SiO}_{2}(\mathrm{~s})+3 \mathrm{C}(\mathrm{s}) \rightarrow \mathrm{SiC}(\mathrm{s})+2 \mathrm{CO}(\mathrm{g})
\end{aligned}
$$

All C/SiC samples were not heat treated before bending tests. These XRD results reflect the influence of experimental temperatures and heated time on the phase structure of $\mathrm{C} / \mathrm{SiC}$ composites, where the heated time is about $15 \mathrm{~min}$. in our tests. Similarly, Hu and Suo et al. found that the oxidation temperature and time affected the structure and mass loss of $\mathrm{C} / \mathrm{SiC}$ composite samples during their mechanical tests [13, 35].

The typical crack propagation morphologies of the $\mathrm{C} / \mathrm{SiC}$ composites after bending tests are observed by SEM at room temperature, as displayed in Fig. 9. It can be found that these actual different cracking paths are in good agreement with those in Fig. 6 provided by DIC, respectively. It also proves the credible of the DIC results above. For bending tests at room temperature, the carbon fibre and $\mathrm{SiC}$ matrix interface may be the weakest region, compared with other mechanical strength of $\mathrm{C} / \mathrm{SiC}$ composites. Since the new formed crack may propagate along the weakest adhesion regions. And these result in the irregular crack path, as shown in Fig. 9(a). However, for the cases at high temperatures, the whole mechanical strength of carbon fibre and $\mathrm{SiC}$ matrix may decrease to the same level of their interface adhesion strength. Moreover, their interface adhesive strength may increase due to the high-temperature oxidation effect. Therefore, the new formed crack path represents an approximately linear, which has been proved by DIC test results (see Figs. 6(b), (c) and (d)). The effects of oxidation time and temperatures on the mechanical properties of $\mathrm{C} / \mathrm{SiC}$ will be systematically studied in further work. 
The SEM observations of fracture morphologies of $\mathrm{C} / \mathrm{SiC}$ composites after bending tests are shown in Fig. 10. It seems that the higher the test temperature is, the more regular, homogeneous and smoother the morphology surface is. The length of the broken carbon fibre in Fig. 10(d) is relatively longer than that in Fig. 10(b) due to the influence of high temperature. It verifies that different experimental temperatures do affect the fracture mechanisms of $\mathrm{C} / \mathrm{SiC}$ composites. Our results may be helpful for further understanding the reliabilities and durability of $\mathrm{C} / \mathrm{SiC}$ composites in service. It can be seen from Figs. 10(f) and (h) that there are a lot of holes because the carbon fibre is completely oxidized. The reason may be that we have to spend about 1 $\mathrm{h}$ or more time to cool the high-temperature furnace, and take out the ruptured $\mathrm{C} / \mathrm{SiC}$ sample after bending tests in the present work. The additional high-temperature time may accelerate the oxidation of carbon fibre materials.

\section{Conclusions}

We developed an in-situ experimental technique by combining SENB and DIC methods at high temperatures, and employed this new technique to investigate the fracture characteristics of $\mathrm{C} / \mathrm{SiC}$ composites. The main conclusions can be summarized as follows,

(1) The nucleation and propagation of the first new crack path of C/SiC composite during bending tests can be in-situ monitored by using DIC technique under 1600 ${ }^{\circ} \mathrm{C}$.

(2) According to the features of the load-deflection curve, the brittle to ductile transition temperature of $\mathrm{C} / \mathrm{SiC}$ composites has been estimated about $1300{ }^{\circ} \mathrm{C}$ in our work. 
(3) The first-crack fracture strength and fracture toughness of $\mathrm{C} / \mathrm{SiC}$ composite gradually decrease, respectively, from $96.97 \mathrm{MPa}$ to $29.73 \mathrm{MPa}$, from 8.55 $\mathrm{MPa} \cdot \mathrm{m}^{1 / 2}$ to $2.26 \mathrm{MPa} \cdot \mathrm{m}^{1 / 2}$ with the increasing of experimental temperatures.

(4) XRD and SEM analysis show that the experimental temperatures play an important role in affecting the mechanical performance of $\mathrm{C} / \mathrm{SiC}$ composites, and changing their fracture mechanisms.

\section{Acknowledgements}

This work was supported by the National Natural Science Foundation of China (Grant Nos. 11102177, 11272276, 11572277), Hunan Provincial Natural Science Foundation of China (14JJ1020), the National Key Scientific Instrument and Equipment Development Project (2012YQ030075). XC acknowledges additional support from NSFC (11172231 and 11372241), ARPA-E (DE-AR0000396) and AFOSR (FA9550-12-1-0159).

\section{References}

[1] H. Mei, T. Ji, X. Chen, Q. Bai, L. Cheng, Mater. Sci. Eng. A, 631 (2015) 33-37.

[2] K. Ding, Y. Fu, H. Su, Y. Chen, X. Yu, G. Ding, J. Mater. Process. Tech., 214 (2014) 2900-2907.

[3] X. Chen, Y. Li, C. Shi, T. Suo, Int. J. Impact Eng., 79 (2015) 75-82.

[4] C.P. Yang, G.Q. Jiao, B. Wang, T. Huang, J. Eur. Ceram. Soc., 35 (2015) 2765-2773.

[5] Z. Luo, X. Zhou, J. Yu, Surf. Coat. Technol., 258 (2014) 146-153.

[6] K. Shimoda, T. Hinoki, H. Kishimoto, A. Kohyama, Compos. Sci. Technol., 71 (2011) 326-332.

[7] H.L. Wang, C.Y. Zhang, Y.S. Liu, D. Han, M. Li, S.R. Qiao, Mater. Design, 36 (2012) 172-176.

[8] K.F. Yan, C.Y. Zhang, S.R. Qiao, D. Han, M. Li, Mater. Sci. Eng. A, 528 (2011) 
1458-1462.

[9] K.F. Yan, C.Y. Zhang, S.R. Qiao, M. Li, D. Han, Mater. Design, 32 (2011) 3504-3508.

[10] H. Yang, X. Zhou, J. Yu, H. Wang, Z. Huang, Ceram. Int., 41 (2015) 11651-11654.

[11] M.W. Bird, R.P. Aune, A.F. Thomas, P.F. Becher, K.W. White, J. Eur. Ceram. Soc., 32 (2012) 3453-3462.

[12] H. Yu, X. Zhou, W. Zhang, H. Peng, C. Zhang, Mater. Design, 44 (2013) 320-324.

[13] S.a. Chen, H. Hu, Y. Zhang, C. Zhang, Q. Wang, Mater. Design, 51 (2013) 19-24.

[14] X. Cao, X. Yin, X. Fan, K. Zhao, H. Luo, L. Cheng, L. Zhang, Ceram. Int., 40 (2014) 6185-6190.

[15] H. Xie, Y. Kang, Opt. Laser. Eng., 65 (2015) 1-2.

[16] D.J. Wu, W.G. Mao, Y.C. Zhou, C. Lu, Appl. Surf. Sci., 257 (2011) 6040-6043.

[17] Standard test method for measurement of fracture toughness E1820-05a. ASTM International, West Conshohocken, 2005.

[18] J. Wan, M. Zhou, X.S. Yang, C.Y. Dai, Y. Zhang, W.G. Mao, C. Lu, Mater. Sci. Eng., A, 581 (2013) 140-144.

[19] M. Zhou, W.B. Yao, X.S. Yang, Z.B. Peng, K.K. Li, C.Y. Dai, W.G. Mao, Y.C. Zhou, C. Lu, Surf. Coat. Technol., 240 (2014) 40-47.

[20] X.S. Yang, J. Wan, C.Y. Dai, Y. Zhang, W.G. Mao, Y.C. Zhou, C. Lu, Surf. Coat. Technol., 223 (2013) 87-91.

[21] W.B. Yao, C.Y. Dai, W.G. Mao, C. Lu, L. Yang, Y.C. Zhou, Surf. Coat. Technol., 206 (2012) 3803-3807.

[22] W.G. Mao, J. Chen, M.S. Si, R.F. Zhang, Z.B. Peng, C.Y. Dai, Q.S. Ma, D.N. Fang, Mater. Sci. Eng. A, 649 (2016) 222-228.

[23] B. Pan, D. Wu, Z. Wang, Y. Xia, Meas. Sci. Technol., 22 (2011) 015701.

[24] B. Pan, D. Wu, Y. Xia, Opt. Laser. Eng., 48 (2010) 841-848.

[25] B. Pan, D. Wu, L. Yu, Appl. Opt., 51 (2012) 4409-4419.

[26] R.J. Roberts, R.C. Rowe, P. York, Int. J. Pharm., 91 (1993) 173-182. 
[27] S. Yashiro, K. Ogi, M. Oshita, Compos. Part B, 43 (2012) 1353-1362.

[28] X. Jing, D. Shi, X. Yang, C. Zhao, Ceram. Int., 41 (2015) 299-307.

[29] R. Wang, W. Li, D. Li, D. Fang, J. Eur. Ceram. Soc., 35 (2015) 2957-2962.

[30] D.T. Wan, Y.W. Bao, Y. Tian, Y. Qiu, H. Zhao, Key Eng. Mater., 633 (2014) 447-450.

[31] L. Wang, J. Liang, G. Fang, J. Alloy Compd., 619 (2015) 145-150.

[32] L. Wei, X. Yang, W. Song, M. Yan, C. Zhao-hui, Ceram. Int., 39 (2013) 463-468.

[33] S. Zhao, X. Zhou, J. Yu, P. Mummery, Mater. Sci. Eng. A, 559 (2013) 808-811.

[34] Y. Xiang, W. Li, S. Wang, Z.-h. Chen, Ceram. Int., 38 (2012) 9-13.

[35] T. Suo, X. Fan, G. Hu, Y. Li, Z. Tang, P. Xue, Carbon, 62 (2013) 481-492. 


\section{Figure captions}

Fig. 1 Schematic of three-dimensional structure of C/SiC composite, (a) unit cell, (b) three-dimensional textile.

Fig. 2 SENB C/SiC composite samples coated by high temperature resistance speckle patterns. The movements of these patterns were monitored by camera and they were used in calculating the displacement or strain of the sample surface by DIC technique, (a) the whole side feature of three representative C/SiC composite samples, (b) a magnification observation of a sample near the notch.

Fig. 3 (a) Schematic of typical SENB test with the aid of DIC. The rectangle with dashed lines shows the monitored region by DIC. (b) high-temperature experimental measurement system in our laboratory.

Fig. 4 Typical loading-deflection-time curves of $\mathrm{C} / \mathrm{SiC}$ composites samples during SENB tests under different temperatures.

Fig. 5 The determination of the new crack nucleation and propagation by using the strain evolution of the selected point ahead of the pre-existed notch.

Fig. 6 In-situ evolution of strain mappings in the monitored surface region during SENB tests, (a) at room temperature, (b) at $1100{ }^{\circ} \mathrm{C}$, (c) at $1300{ }^{\circ} \mathrm{C}$, (d) at $1600^{\circ} \mathrm{C}$.

Fig. 7 Relationships of the first-crack strength and fracture toughness of C/SiC composites and different test temperatures.

Fig. 8 Analysis of XRD patterns of C/SiC composites after SENB tests under different temperatures.

Fig. 9 SEM observations of surface morphology of C/SiC composites after bending tests, (a) bending test at room temperature, (b) bending test at $1100{ }^{\circ} \mathrm{C}$, (c) bending test at $1600{ }^{\circ} \mathrm{C}$.

Fig. 10 SEM observations of the ruptured cross-section morphology of $\mathrm{C} / \mathrm{SiC}$ composites after bending tests, (a) and (b) bending test at room temperature, (c) and (d) bending test at $1100{ }^{\circ} \mathrm{C}$, (e) and (f) bending test at $1300{ }^{\circ} \mathrm{C}$, (g) and (h) bending test at $1600^{\circ} \mathrm{C}$. 


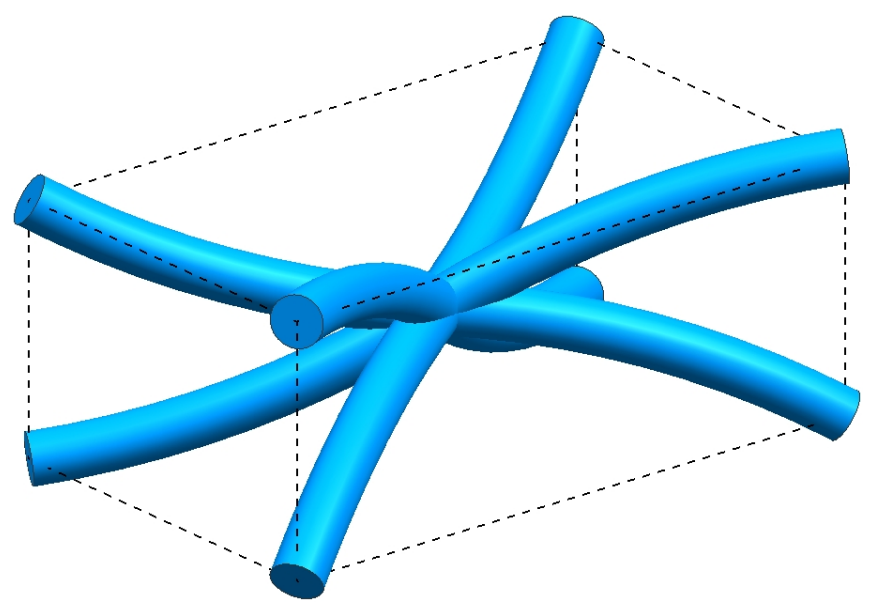

(a)

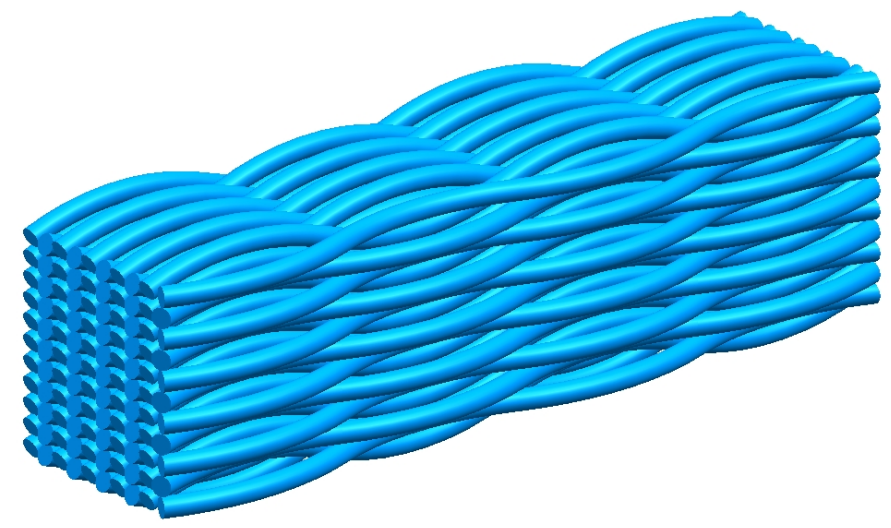

(b)

Fig. 1 

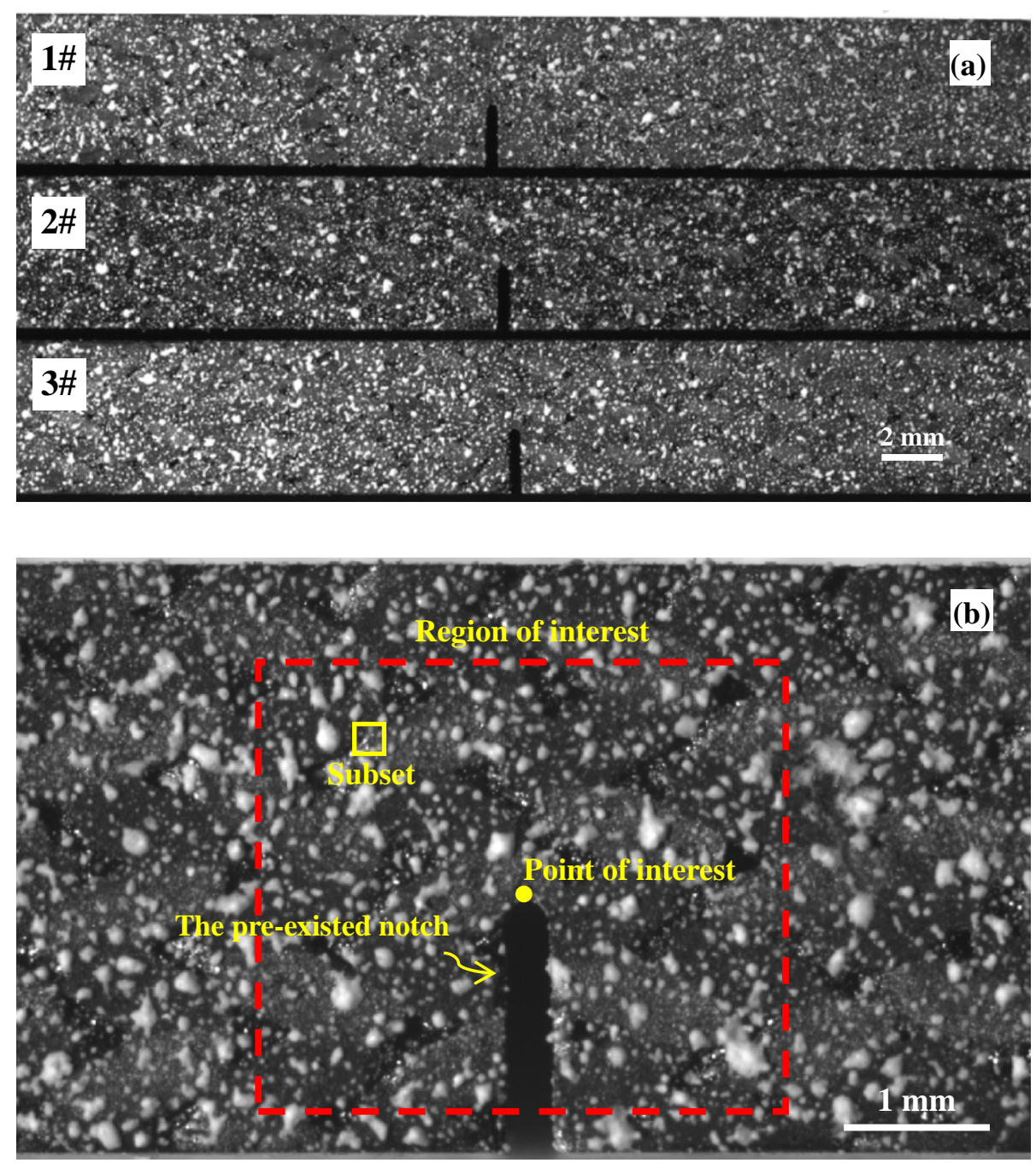

Fig. 2 


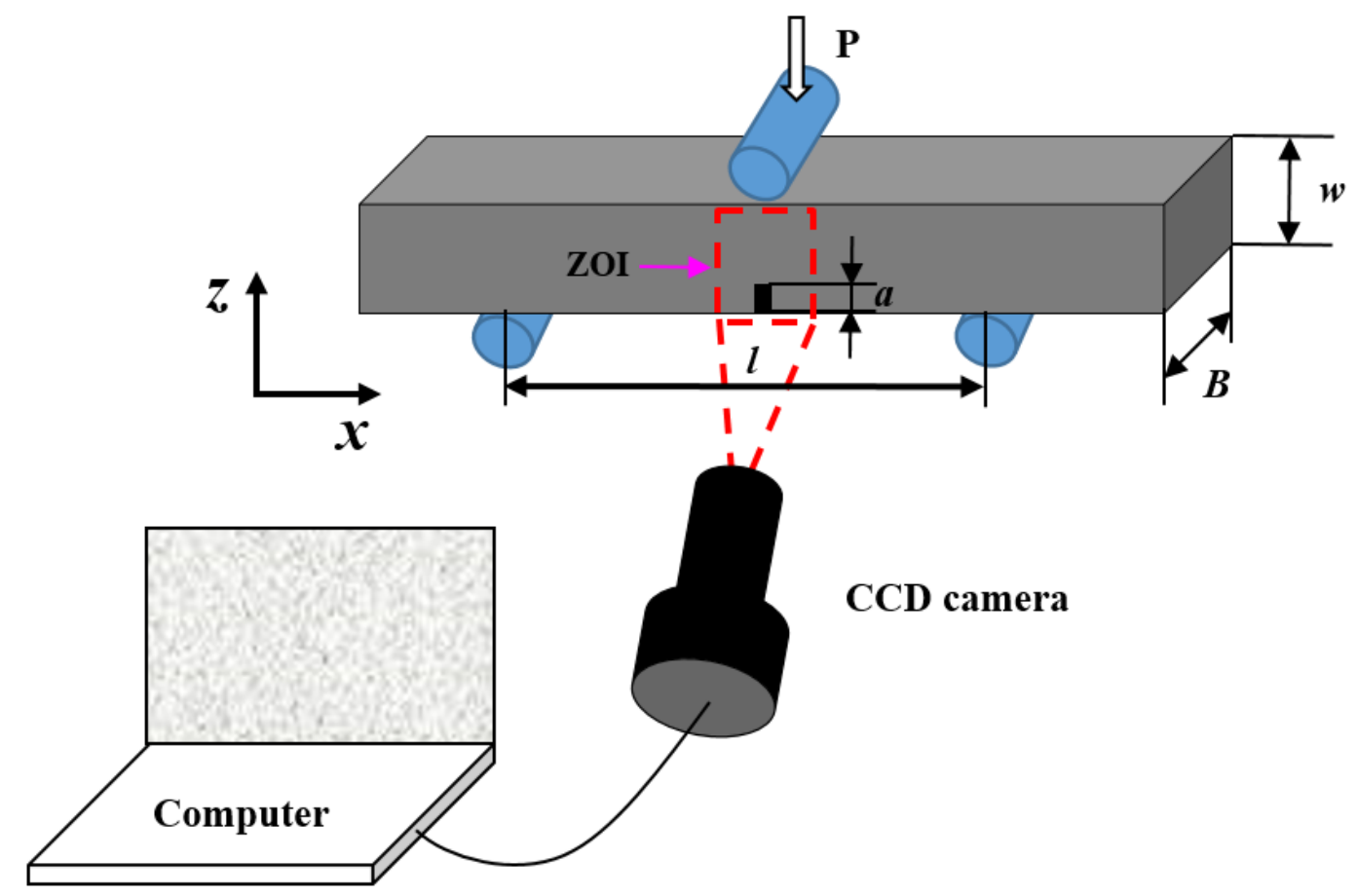

(a)

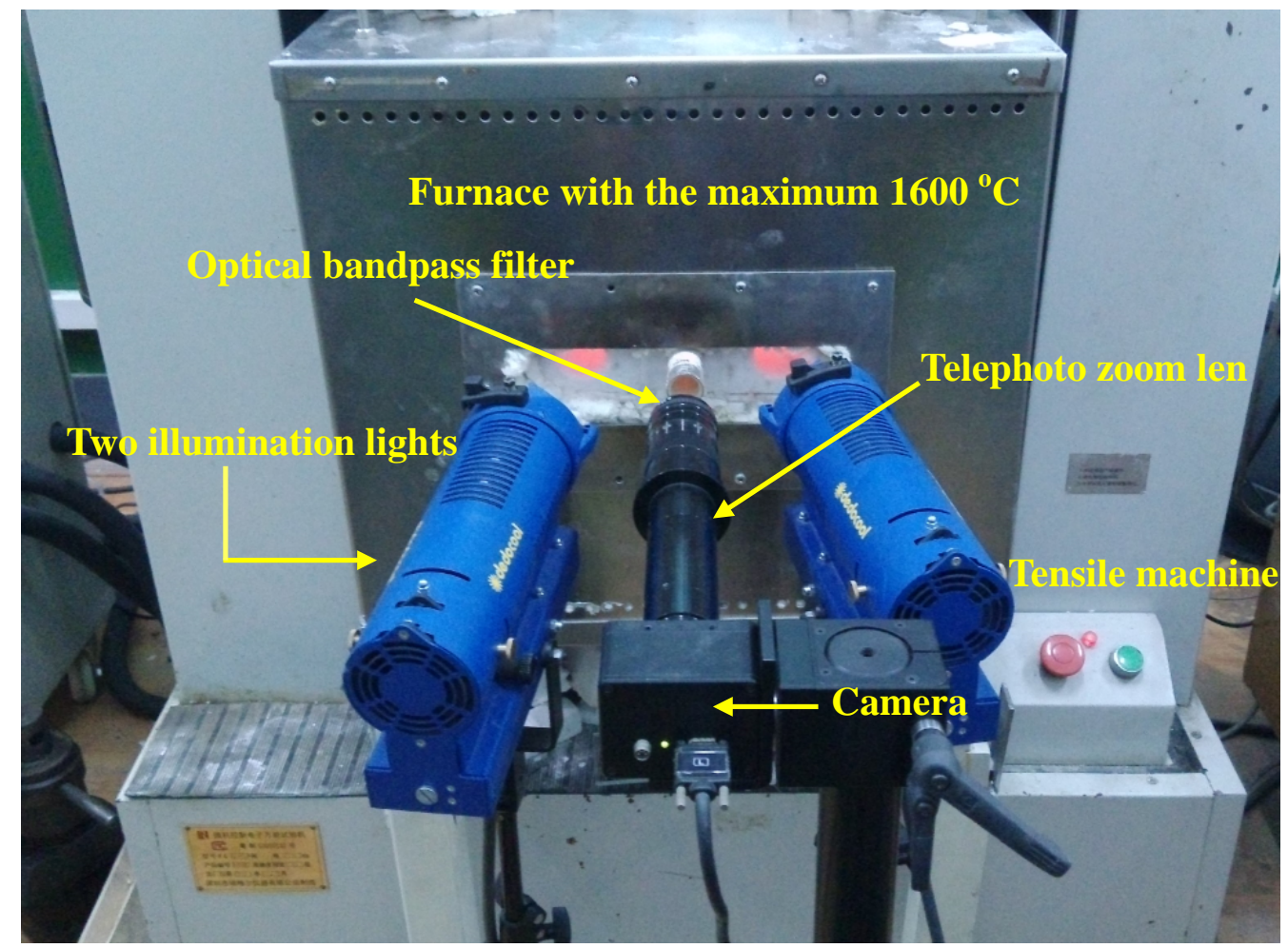

(b)

Fig. 3 


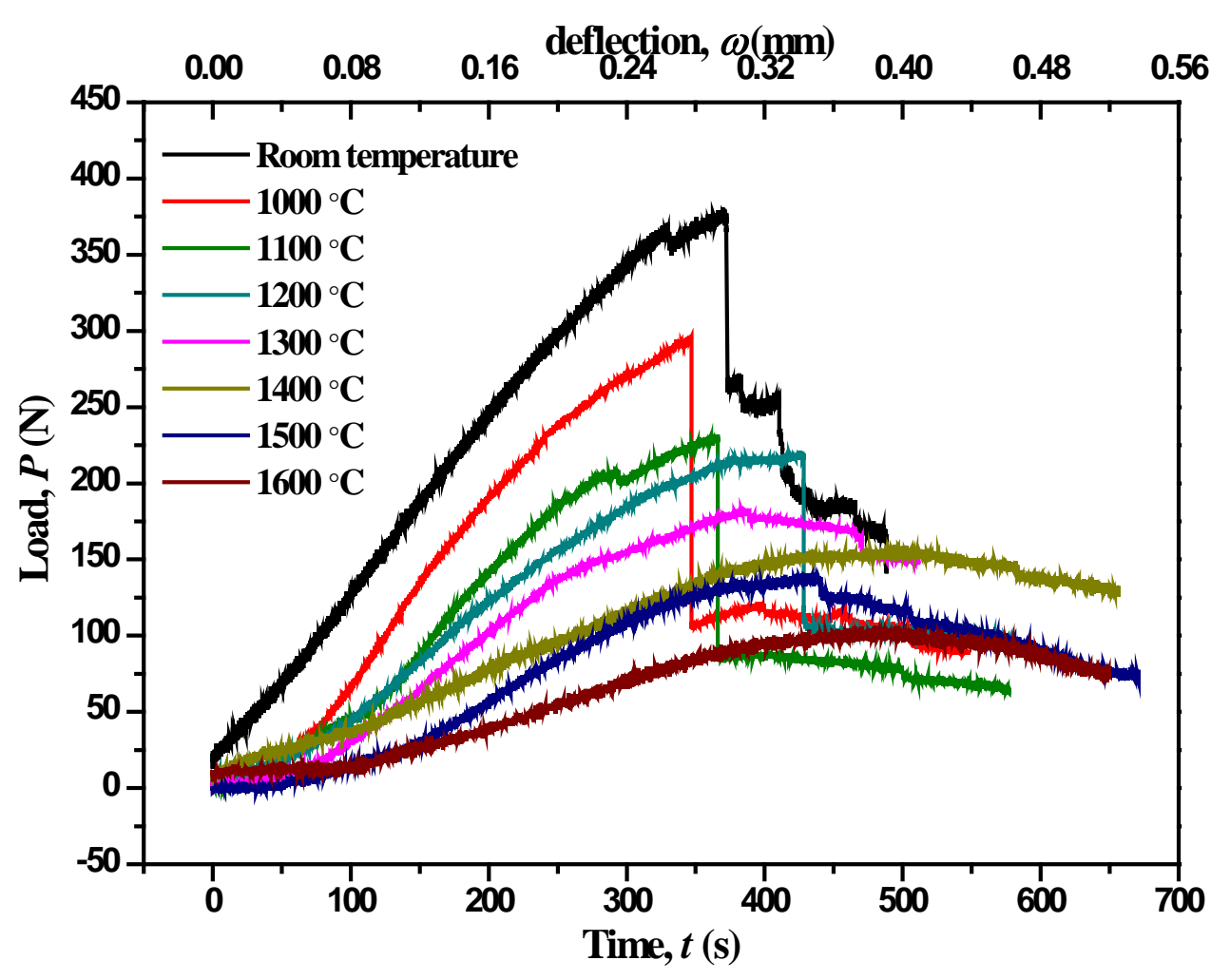

Fig. 4 


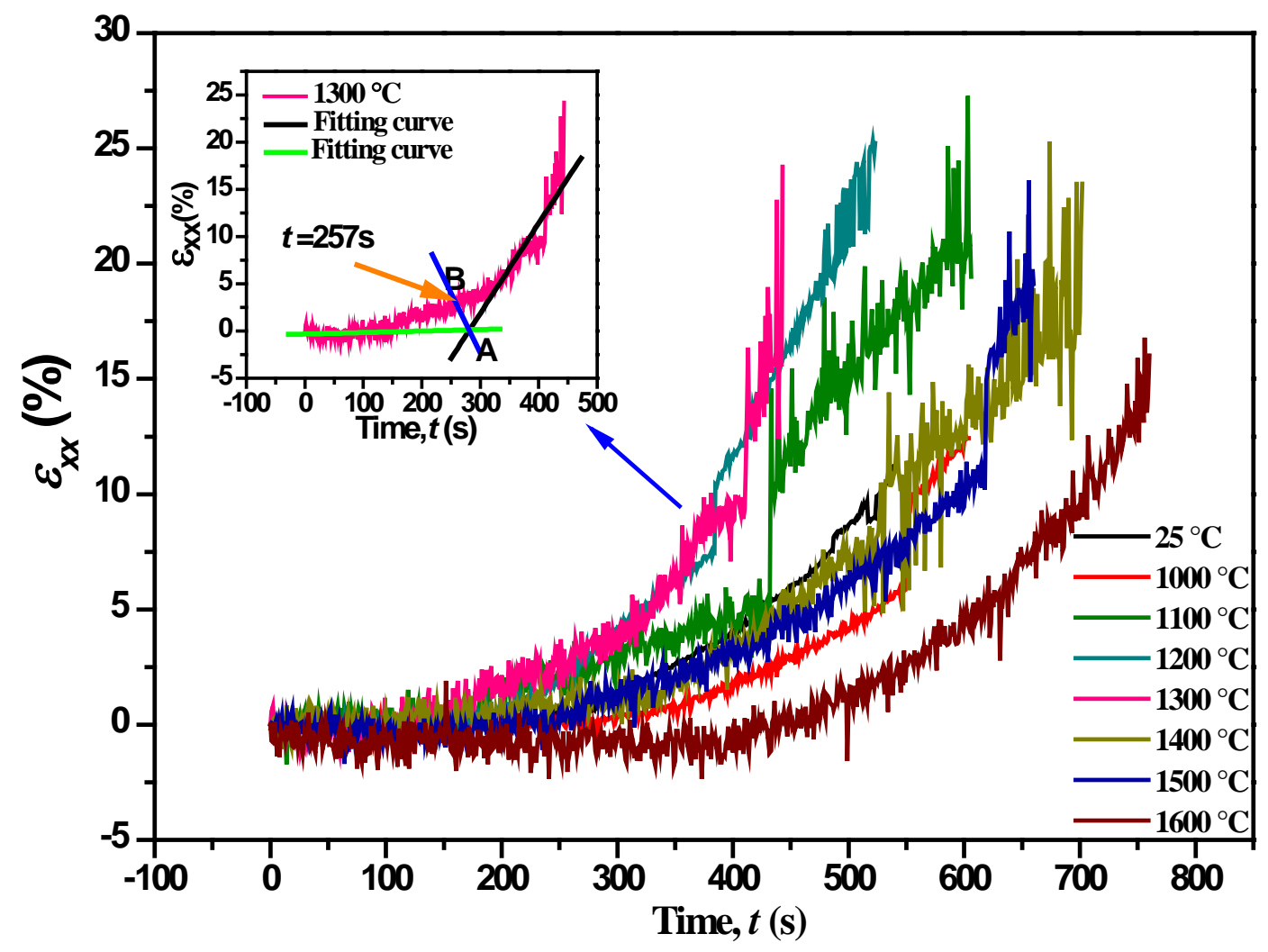

Fig. 5 


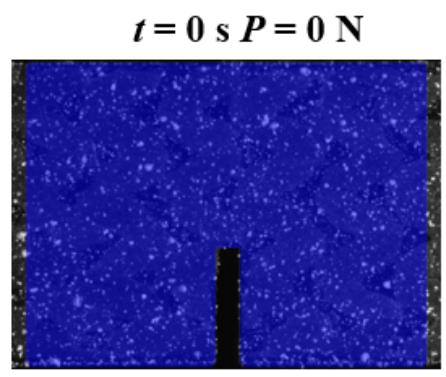

$t=369 \mathrm{~s} P=381.0 \mathrm{~N}$
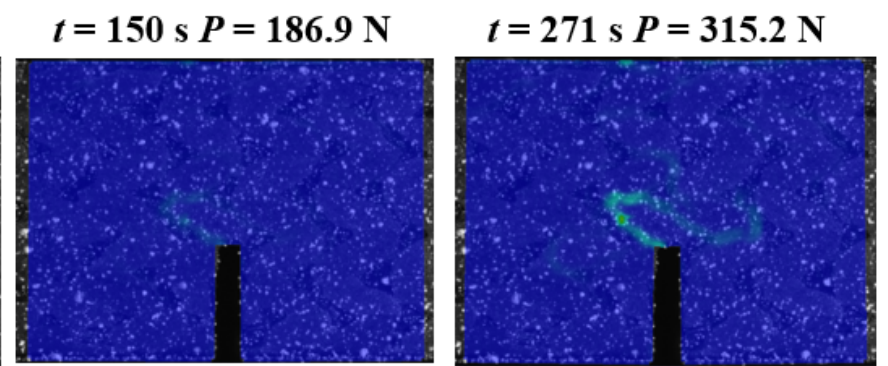

$\varepsilon_{x x}$

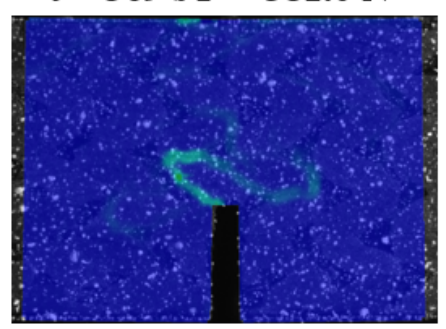

$t=399$ s $P=251.2 \mathrm{~N}$
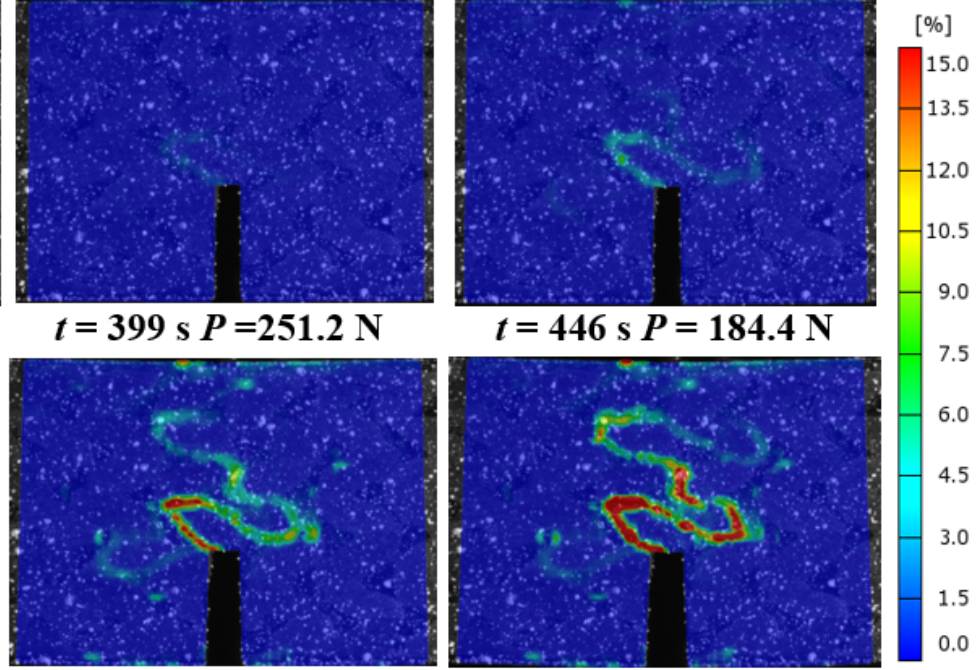

(a)
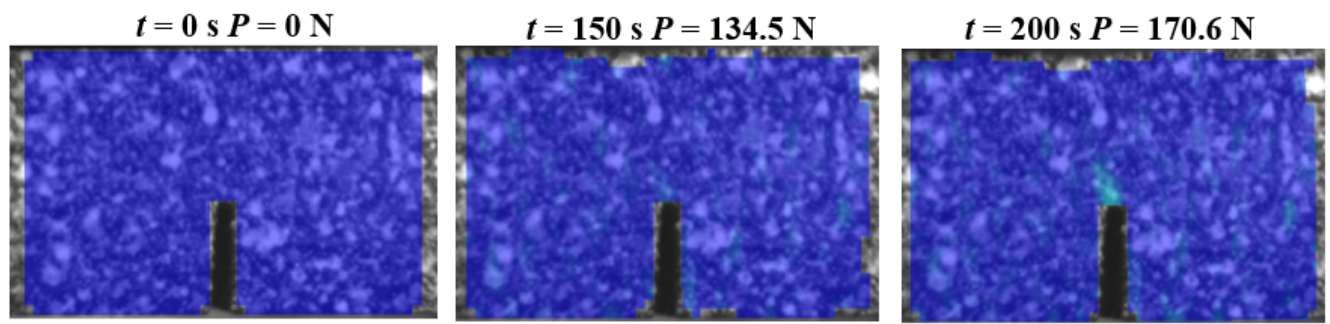

$\varepsilon_{x x}$
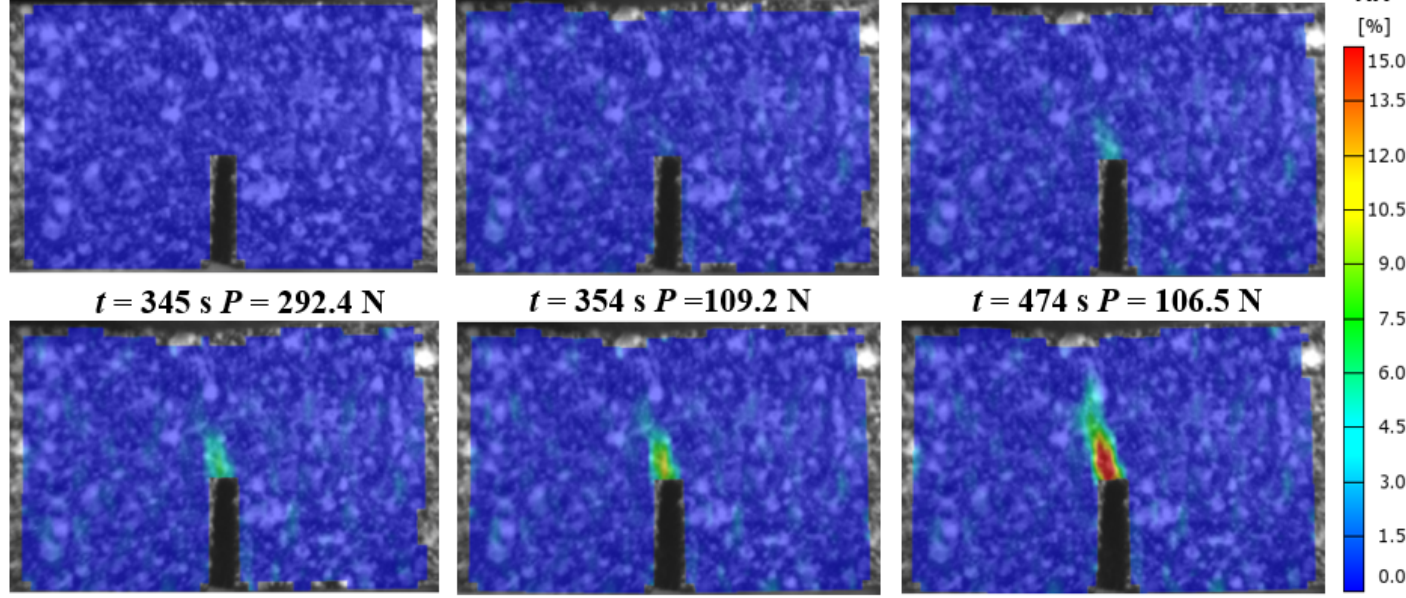

(b)

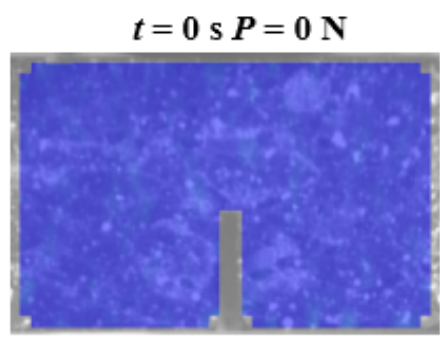

$t=382 \mathrm{~s} P=183.2 \mathrm{~N}$

$t=150 \mathrm{~s} P=65.9 \mathrm{~N}$

$t=257 \mathrm{~s} P=141.7 \mathrm{~N}$

$\varepsilon_{x x}$

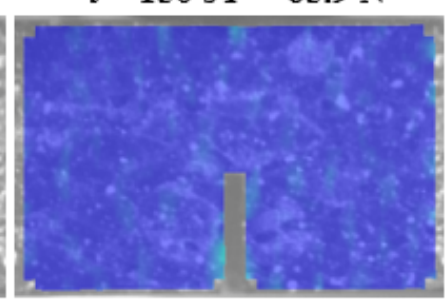

$t=441 \mathrm{~s} P=170.8 \mathrm{~N}$

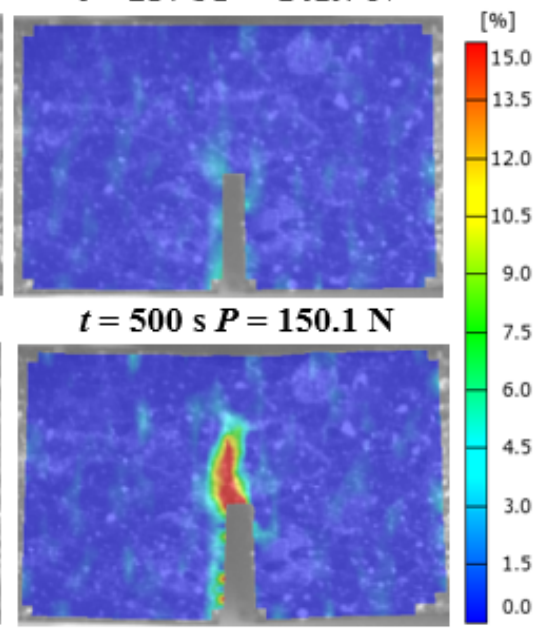

(c) 


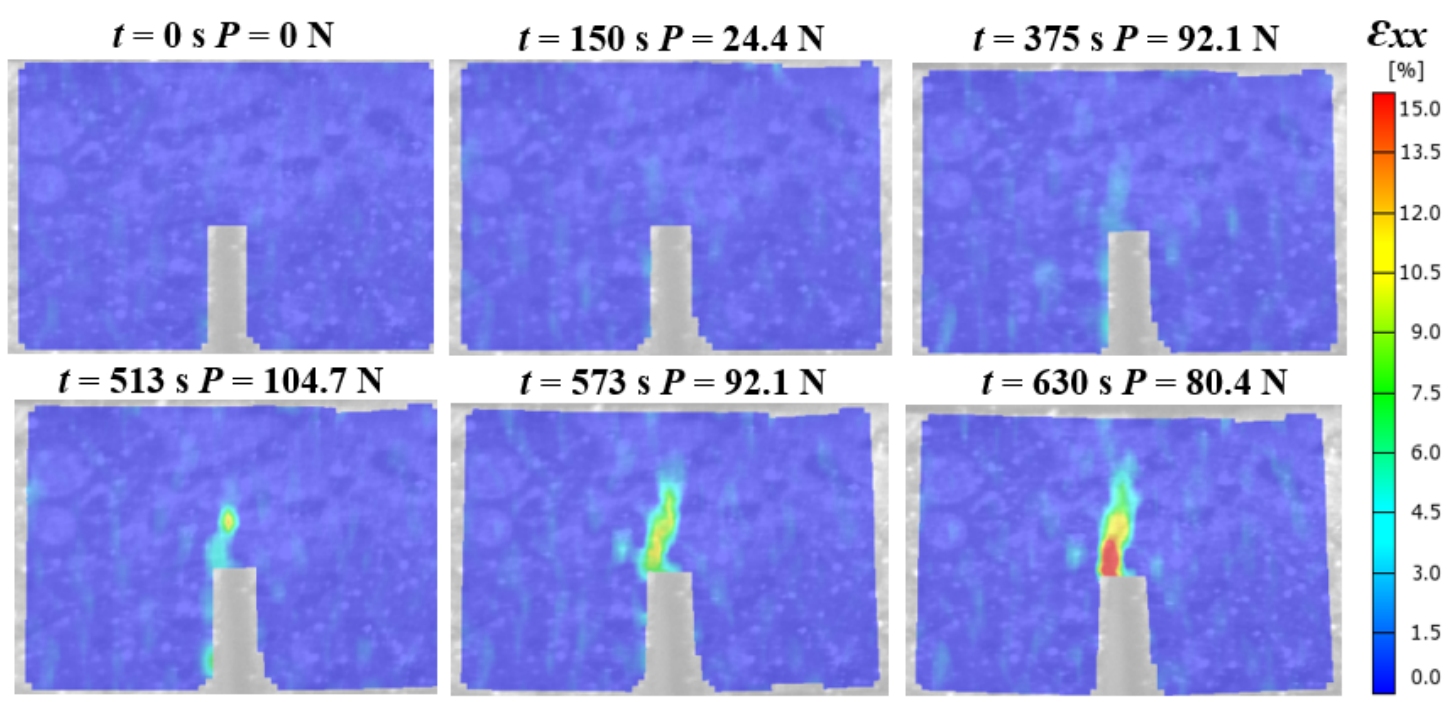

(d)

Fig. 6 


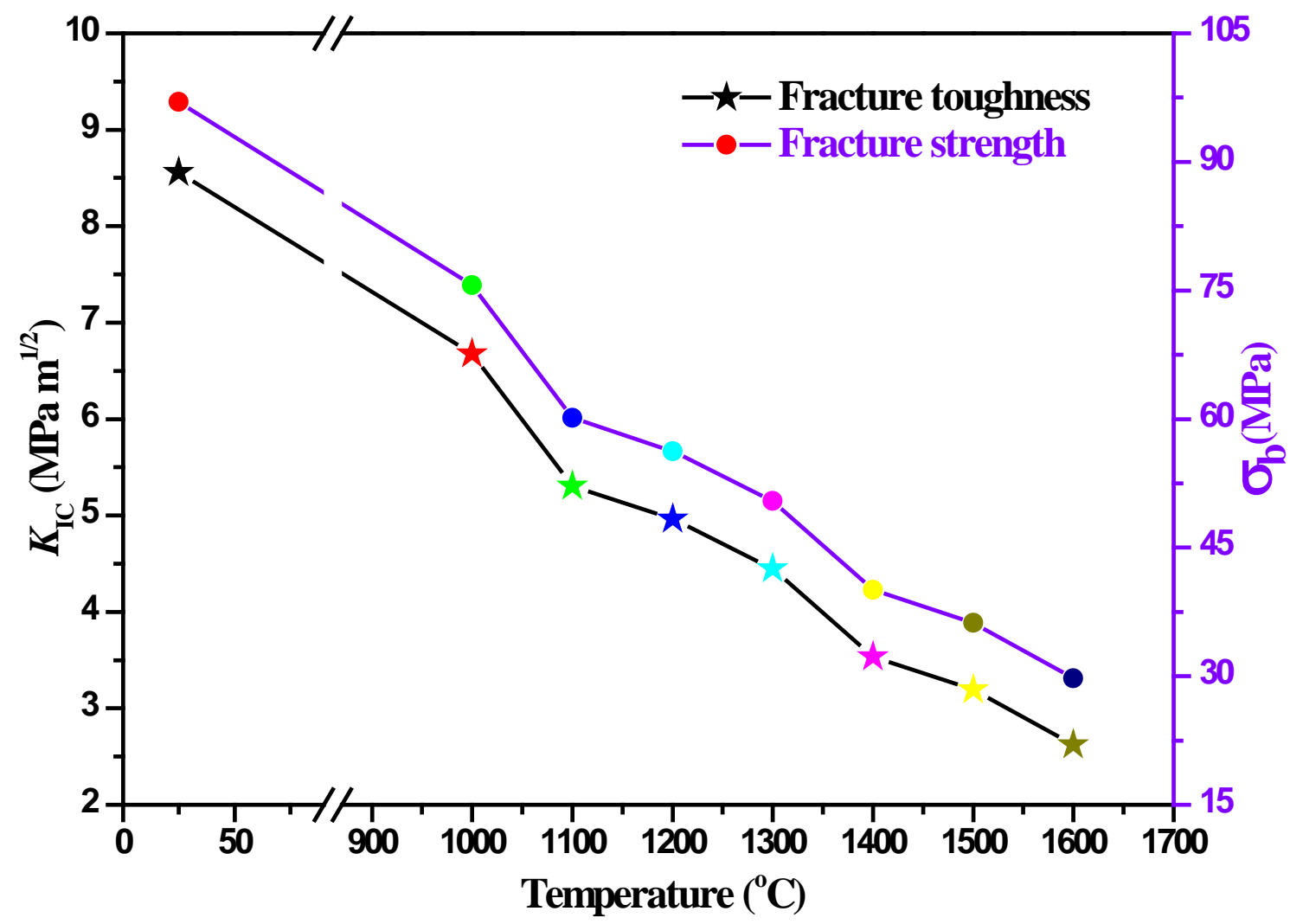

Fig. 7 


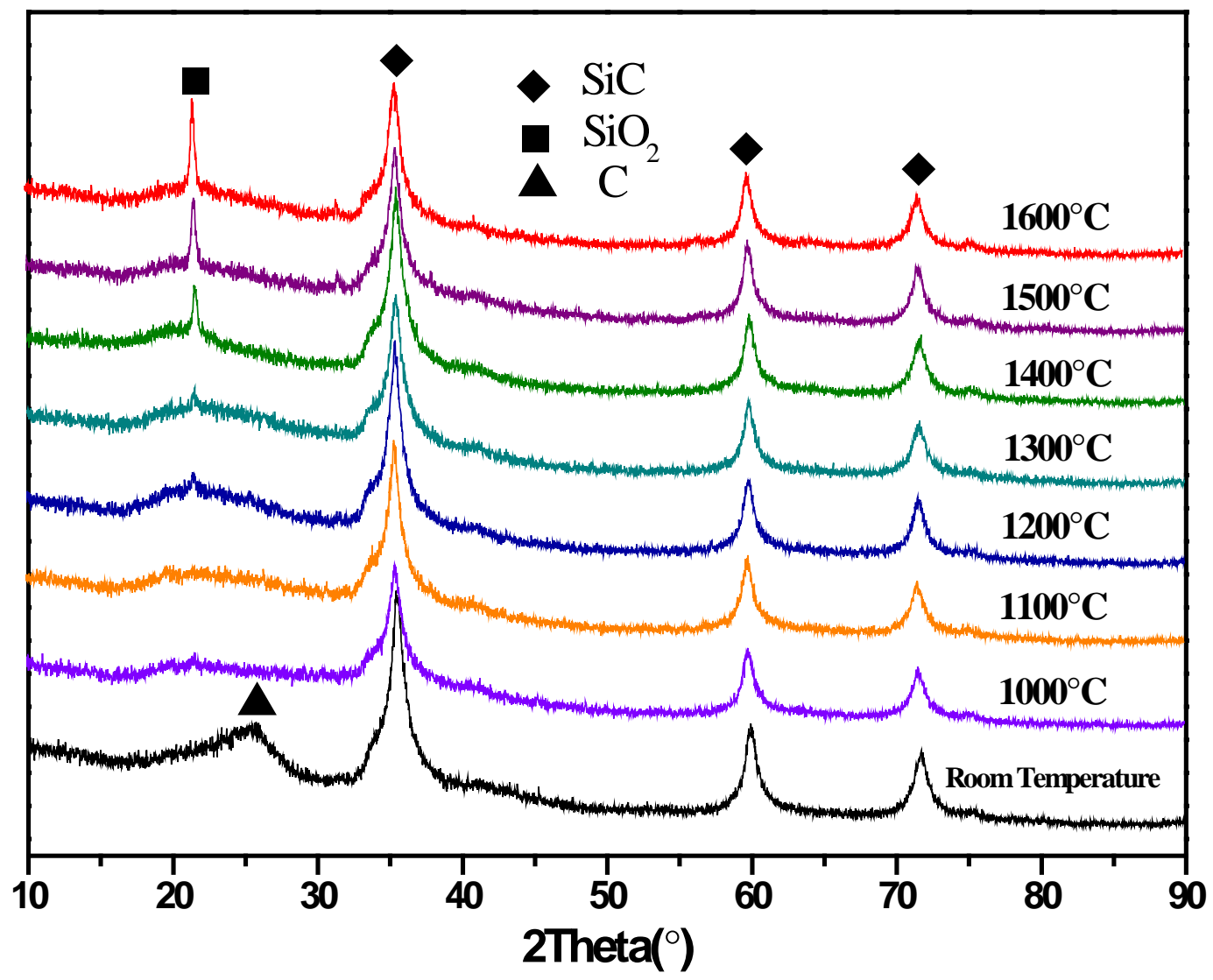

Fig. 8 

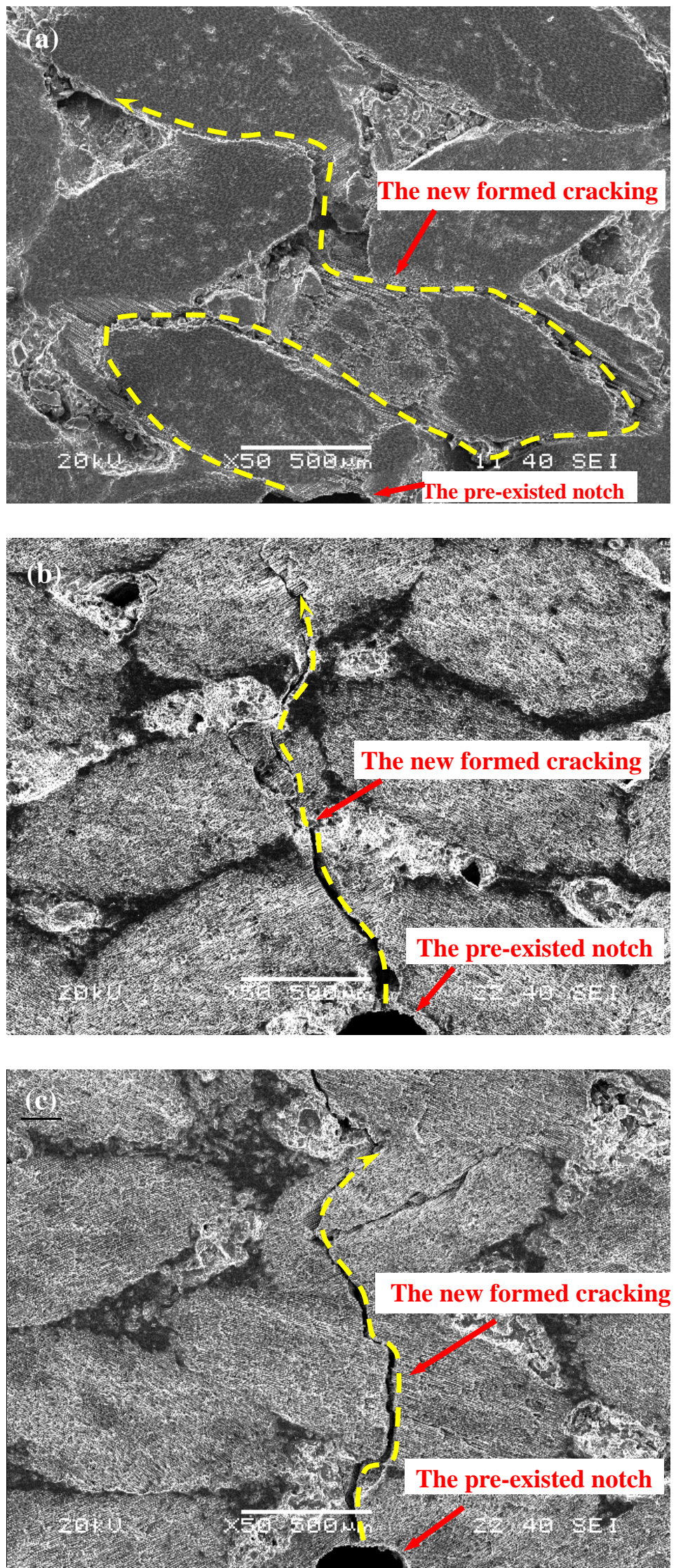

Fig. 9 